ROCZNIKI NAUK SPOŁECZNYCH

Tom 13(49), numer 1 - 2021

DOI: https://doi.org/10.18290/rns21491.11

DARIUSZ WADOWSKI

\title{
PAMIĘĆ ZBIOROWA I DZIENNIKARSTWO NEWSOWE
}

\section{WPROWADZENIE}

Komunikacja jest procesem niezwykle ważnym dla pamięci zbiorowej, bez niej pamięć zbiorowa nie byłaby możliwa, a przeszłość byłaby przechowywana wyłącznie w umysłach tych osób, które bezpośrednio jej doświadczyły. Ze względu na dzisiejszą wszechobecność komunikacji medialnej to właśnie mediom przypada kluczowa rola w konstruowaniu wyobrażeń o przeszłości funkcjonujących w obrębie różnych grup i zbiorowości, a także w konkretnych jednostkach. Medialnie ukształtowane i zapośredniczone reprezentacje przeszłości odgrywają obecnie bardziej znaczącą rolę w budowaniu ogólnych zasobów pamięci zbiorowej aniżeli narracje profesjonalnych historyków zawarte w podręcznikach i nauczane w szkole. Bardziej odpowiadają też wrażliwości i kompetencjom współczesnych uczestników kultury popularnej, gdyż przemawiają do nich za pomocą zrozumiałych kodów obrazu, emocji, dramatyzacji i skrótu. Można powiedzieć, że ze względu na fakt wszechobecności medialnych komunikatów, powszechną do nich dostępność oraz możliwość nieskończonego w zasadzie powielania i przypominania, przeważająca część ogólnych zasobów pamięci zbiorowej to medialnie ukształtowane obrazy i opowieści o przeszłości.

W przestrzeni medialnej jest obecnych wiele różnych reprezentacji przeszłości konkurujących ze sobą o uwagę i uznanie ze strony odbiorców. Niektóre $\mathrm{z}$ tych reprezentacji są tworzone intencjonalnie i w założeniu mają coś upamiętniać, przypominać albo wręcz rekonstruować wybrany fragment zbiorowej przeszłości. Inne są pozornie pozbawione ukierunkowania na przeszłość, a odwołania historyczne dochodzą w nich do głosu niejako bezwiednie

Dr hab. DARIUSZ WADOwSKI - Katedra Kultury Medialnej, Instytut Dziennikarstwa i Zarządzania, Wydział Nauk Społecznych, Katolicki Uniwersytet Lubelski Jana Pawła II; adres do korespondencji: Al. Racławickie 14, 20-950 Lublin; e-mail: dariusz.wadowski@kul.pl; ORCID: https://orcid.org/0000-0001-8936-9557. 
i przypadkowo. Do takich reprezentacji należą przede wszystkim te, które są kształtowane w obrębie dziennikarstwa newsowego czy informacyjnego.

\section{BADANIA ROLI DZIENNIKARSTWA NEWSOWEGO W KSZTAŁTOWANIU ZBIOROWEJ PAMIĘCI}

Dziennikarstwo newsowe nie jest obszarem zbyt często eksplorowanym przez badaczy zbiorowej pamięci. Dominujące tendencje społeczno-kulturowe, które preferują teraźniejszość i szybkość, sprawiają również, że sami dziennikarze także wolą być kojarzeni z dostarczaniem świeżych i aktualnych informacji aniżeli z tematyką należącą do przeszłości. Starają się oni o dostarczenie pierwotnej, tworzonej „na gorąco" wersji wydarzeń, pozostawiając ich porządkowanie i interpretację profesjonalnym historykom, ewentualnie publicystom (Zelizer, 2008, s. 380). Ich aktywność komunikacyjna jest więc przede wszystkim podporządkowana potrzebom chwili oraz zobowiązaniom względem publiczności dostarczania aktualnych bieżących informacji. Z drugiej jednak strony problematyka pamięci jest bardzo atrakcyjna dla dziennikarzy, którzy na różne sposoby ją eksploatują i starają się współkształtować. Leon Dyczewski uważa wręcz, że wśród dziennikarzy staje się ona modna (Dyczewski, 2011, s. 144). Dziennikarze informacyjni intensywnie uczestniczą w ogólnospołecznej ,pracy nad pamięcią”, przy czym zakres i formy ich zaangażowania zależą od różnego rodzaju uwarunkowań: politycznych, ekonomicznych, kulturowych, instytucjonalnych, technologicznych czy też gatunkowych.

$\mathrm{Z}$ tych względów dziennikarstwo informacyjne jako przestrzeń konstruowania i upowszechniania różnych wersji przeszłości staje się przedmiotem zainteresowania badaczy funkcjonujących w ramach szerokiego, wielodyscyplinarnego i wielokierunkowego nurtu studiów nad pamięcią medialną (media memory studies). Włączenie dziennikarstwa w obszar naukowych eksploracji aktywności pamięciotwórczej nastąpiło stosunkowo późno, bowiem dopiero w latach 80. XX wieku. Zaczęto wtedy dostrzegać nowe, słabo dotychczas doceniane aspekty funkcjonowania pamięci, a przede wszystkim fakt funkcjonowania różnych form zbiorowego pamiętania, upamiętniania i rekonstruowania przeszłości w kontekście bieżących wydarzeń, których społeczna recepcja zależy właśnie od dziennikarzy. Skupiano się na zakresie i sposobach wykorzystywania przez dziennikarzy materiałów archiwalnych, a także funkcjach i znaczeniu różnego rodzaju odwołań do przeszłości obecnych w newsach. W jednym z pionierskich opracowań dotyczących tej tematyki Kurt Lang 
i Gladys A. Lang stwierdzili, że dla dziennikarstwa informacyjnego niemożliwe jest całkowite oderwanie się od przeszłości i jej ignorowanie, dziennikarze bowiem powszechnie korzystają z zasobów pamięci kulturowej społeczeństwa oraz bazują na zdolności pamiętania i zapominania odbiorców (Lang i Lang, 1989). Wykorzystanie przez dziennikarzy newsowych wspólnych zasobów pamięci jest wprost nieuniknione, ponieważ - jak zauważa Barbie Zelizer - „Przeszłość pozostaje jednym z najbogatszych repozytoriów dostępnych dla dziennikarzy w wyjaśnianiu aktualnych wydarzeń” (Zelizer, 2008, s. 381). Tym bardziej że prowadzone badania wykazują rosnącą tendencję dziennikarzy informacyjnych raczej do interpretowania aniżeli czystego relacjonowania wydarzeń; interpretowania wykorzystującego także różne konteksty historyczne i treści zbiorowej pamięci (Barnhurst, 2003).

B. Zelizer należy grona badaczy, którzy dziennikarską pracę nad pamięcią zbiorową czynią głównym przedmiotem swego zainteresowania. Jej badania dotyczyły między innymi znaczenia instytucji medialnych w kształtowaniu pamięci (Zelizer, 1993), dziennikarskich sposobów relacjonowania, przypominania i upamiętniania zabójstwa prezydenta J.F. Kennedy'ego (Zelizer, 1992) oraz znaczenia pamięci w relacjach z konfliktów w Zatoce Perskiej, Bośni i Rwandzie (Zelizer, 2004). Michael Schudson z kolei poświęcił swoje studium dziennikarskim sposobom przedstawiania i interpretowania afery Watergate (Schudson, 1992). Formy odwołań do przeszłości wykorzystywane podczas relacjonowania uroczystości upamiętniających Holocaust były przedmiotem analiz m.in. Eyala Zandberga, Orena Meyersa i Motti Neigera (Zandberg, Meyers i Neiger, 2012). E. Zandberg skupiał się także na źródłach autorytetu dziennikarzy oferujących publiczności własne interpretacje przeszłości i teraźniejszości (Zandberg, 2010). Jill A. Edy i Miglena Daradanova analizowały proces gromadzenia i porządkowania informacji oraz tworzenia newsów dotyczących katastrofy promu Columbia, wykorzystując doświadczenia uprzedniej katastrofy promu Challenger (Edy i Daradanova, 2006). Sabina Mihelj natomiast badała newsy telewizyjne w krajach byłej Jugosławii pod kątem wykorzystania $\mathrm{w}$ nich treści dotyczących narodowej przeszłości (Mihelj, 2009).

Wymienione wybrane przykłady badań koncentrujących się na działaniach dziennikarzy newsowych w zakresie kształtowania, interpretowania i reinterpretowania zbiorowej przeszłości ukazują zarówno wielonurtowość zainteresowań badaczy pamięci medialnej, jak również wielość sposobów obecności reprezentacji przeszłości w dziennikarskich wytworach. B. Zelizer w szerokim i mocno zróżnicowanym nurcie refleksji nad rolą dziennikarstwa w kształtowaniu 
pamięci wyodrębnia dwa podstawowe kierunki: jeden skoncentrowany na treści, a drugi na formie (Zelizer, 2008, s. 383-384). W tym pierwszym chodzi o wszelkiego rodzaju odwołania do przeszłości, która jest traktowana jako środek wyjaśniania aktualnych wydarzeń. Potrzeba skupienia się dziennikarza na historii wynika z samego tematu, i to temat wymusza konieczność uwzględnienia tego, co było. Przykładami mogą być tutaj studia Orena Meyersa nad upamiętnianiem Holocaustu (Meyers, 2002) lub analizy Carolyn Kitsch dotyczące sposobów opowiadania o celebrytach (Kitch, 2005). Drugi kierunek, koncentrujący się na formie, podkreśla funkcjonowanie pamięci przeszłości jako narzędzia wyjaśniania teraźniejszości. $Z$ takim jej wykorzystaniem mamy do czynienia przede wszystkim podczas stosowania przez dziennikarzy różnego rodzaju porównań i analogii historycznych. Wymownych przykładów dostarcza tutaj chociażby wspomniane studium B. Zelizer nad relacjami z wojny w Zatoce Perskiej.

\section{NEWSY JAKO MEDIA PAMIĘCI}

Gatunek newsów stosunkowo rzadko jest postrzegany jako nośnik pamięci. Ten typ komunikowania medialnego jest skoncentrowany przede wszystkim na chwili obecnej i zawiera informacje o wydarzeniach zachodzących ,tu i teraz”. Ze względu na ciągłe wytwarzanie nowych newsów, ich nieprzerwany napływ, zastępowanie zdezaktualizowanych nowymi sprzyjają one raczej stanom zbiorowej i indywidualnej amnezji, aniżeli kształtują i utrwalają pamięć zbiorowości (Huyssen, 1995). Jedynie newsy archiwalne, zachowane z dawnych czasów w formie drukowanej, nagrań audio lub wideo, które analizują badacze mediów lub wykorzystują dziennikarze, bywają uznawane za pamięciotwórcze.

Możliwe jest jednak nieco inne spojrzenie na newsy, bardziej uwzględniające pomijane często ich aspekty i funkcje. Skoro Marcin Kula uważał, że „nośnikiem pamięci o przeszłości, przynajmniej potencjalnej, jest dosłownie wszystko" (Kula, 2002), mogą również być nim i newsy.

Można je bowiem, zgodnie ze stanowiskiem Astrid Erll, traktować jako media pamięci, a więc wszelkiego rodzaju obiektywizacje treści pamięciowych i pamięciotwórczych wykorzystywane w procesach komunikacyjnych (Erll, 2008).

W strukturze mediów pamięci A. Erll wyodrębnia cztery podstawowe wymiary. Pierwszym jest wymiar materialny, który tworzą technologie i narzędzia 
służące przekazowi informacji. W przypadku newsów istotne zatem będą wszystkie aspekty technologiczne, kanały ich upowszechniania, narzędzia techniczne wykorzystywane do ich tworzenia i przekazywania. Drugim wymiarem mediów pamięci są oferty, czyli konkretne obiektywizacje i formy zapośrednioczonej pamięci. Należą tu formalne i estetyczne reguły budowania newsów, wykorzystywane schematy i skrypty, metafory i struktury narracyjne, a także zawartość treściowa newsów. Newsy posiadają swoiste zasady konstrukcyjne, a ich treścią stają się tylko niektóre wydarzenia, których selekcji towarzyszą pewne kryteria. Ich źródłem może być zarówno dziennikarska rutyna, antycypowane oczekiwania odbiorców, polityka danej redakcji, jak też po prostu medialna atrakcyjność tematu. Trzecim wymiarem jest wymiar społeczny, gdzie zwraca się uwagę na fakt, iż wszystkie media są wytworem społecznym, funkcjonują w pewnym społecznym otoczeniu, uwarunkowane są zjawiskami i procesami w nim zachodzącymi i uczestniczą $\mathrm{w}$ procesach komunikacji w obrębie konkretnych grup społecznych. W tym też wymiarze zachodzi proces instytucjonalizacji w medium pamięci, a zatem to on odpowiada za kulturowe przypisanie newsom pamięciotwórczej roli. Ostatni wymiar dotyczy społecznego wykorzystania mediów pamięci, a mówiąc precyzyjniej chodzi o ich rolę w kształtowaniu tożsamości społeczno-kulturowej, w edukacji szkolnej, w tworzeniu różnego rodzaju archiwów i repozytoriów, a wreszcie w kształtowaniu zasobów pamięci jednostkowej i indywidualnych sposobów pamiętania. A. Erll stwierdza, że media pamięci „Zawsze materializują się na tle istniejących konfiguracji pamięci. Przestrzenie doświadczeń i horyzonty oczekiwań, struktury wiedzy, praktyki pamięci, podważanie pamięci i konkurencyjna pamięć kształtują produkcję, przekaz i odbiór pamięci” (Erll, 2018, s. 198).

Newsy jako szczególna postać mediów pamięci, również nie funkcjonują zatem w izolacji względem innych procesów pamięciowych i pamięciotwórczych, przy czym możemy mówić tu o dwóch aspektach ich funkcjonalizacji jako mediów pamięci: o aspekcie produkcji i o aspekcie odbioru (Erll, 2018, s. 197). W przypadku funkcjonalizacji po stronie produkcji chodzi o określony sposób doboru i kodowania informacji w celu wywołania procesów pamięciowych, natomiast w przypadku funkcjonalizacji po stronie odbioru chodzi o traktowanie przez odbiorców newsów jako impulsu, sygnału lub środka do podejmowania działań intelektualnych, emocjonalnych bądź innych związanych z procesami pamięciowymi. Podobnie jak podczas rozwoju masowej prasy, również dziś newsy, dostarczając zapośredniczonych, uschematyzowanych i wielopostaciowych reprezentacji przeszłości, integrują współczesne pluralistyczne 
społeczeństwa, budując wspólnotę kodów, wątków, tematów i standardów interpretacyjnych.

Zdaniem A. Erll wszystkie media pamięci, również newsy - jak je tutaj traktujemy - pełnią trzy podstawowe funkcje: magazynowanie, cyrkulacja i cue (wywoływanie) (Erll, 2018, s. 199-201). Służą one zatem przechowywaniu wiedzy o pewnych wydarzeniach i zapewnianiu dostępu do niej, upowszechnianiu wśród publiczności informacji dotyczących tych wydarzeń oraz wywoływaniu wspomnień, skojarzeń i innych aktów pamięci pod wpływem kontaktu odbiorców z taką informacją. W zależności od swojego przedmiotu oraz kontekstu komunikacyjnego, w jakim się pojawiają, newsy mogą jednocześnie pełnić wszystkie bądź tylko niektóre z tych funkcji.

\section{ISTOTA DZIENNIKARSKIEJ PRACY NAD PAMIĘCIĄ}

Biorąc pod uwagę różne wytwory działalności medialnej zazwyczaj podkreśla się, że produkty pracy dziennikarzy są bliżej „prawdziwej” historii aniżeli inne medialne oferty, takie jak na przykład filmy fabularne. Dziennikarze nie tylko tworzą pierwsze wersje opisu wydarzeń, lecz także kształtują wspomnienia i swoimi materiałami stymulują do podejmowania zbiorowej aktywności w zakresie postaw względem historii i jej poszczególnych elementów. Dziennikarze wskazują odbiorcom, czy przeszłość jest w ogóle ważna i godna pamiętania, jakie jej elementy warto wspominać, w jaki sposób oceniać przeszłe wydarzenia i postacie, jak wiązać je z chwilą obecną oraz projektami i przewidywaniami przyszłości. Dokonując selekcji wydarzeń i postaci, ku którym zwracają swoją uwagę, nakreślają granice między „nami” a „innymi”, przeszłością „naszą” i „obcą” oraz sugerują określone postawy wobec składników pamięci całego społeczeństwa i jego partykularnych segmentów. Tym samym stają się jednymi z głównych aktorów współdecydujących o aktualnym i przyszłym kształcie zbiorowej pamięci i społecznych wyobrażeniach przeszłości. Jako część niejednorodnej wewnętrznie opiniotwórczej elity roszczą sobie pretensje do interpretowania przeszłości i nadawania jej sensu (Dyczewski, 2011, s. 139). Są też zaangażowani w dokumentowanie tego, co dzieje się z pamięcią, w jaki sposób ona funkcjonuje, czyli spełniają rolę kronikarzy pamięci, gromadząc, porządkując i hierarchizując informacje na ten temat.

Bardziej lub mniej wyraźna obecność odniesień do przeszłości w dziennikarstwie newsowym jest realizowana na podstawie dwóch zestawów reguł, które pozostają względem siebie w dynamicznych relacjach. Pierwszy zestaw 
stanowią zasady definiujące podstawowe standardy pracy dziennikarza informacyjnego, takie jak bezstronność, obiektywność, jasność, wiarygodność źródeł, aktualność. Rządzą one procesem gromadzenia i selekcjonowania informacji oraz nadawania im określonej formy gatunkowej. Temu pierwszemu zestawowi towarzyszą zasady regulujące działanie pamięci zbiorowej, a przede wszystkim związane z pełnionymi przez nią funkcjami tożsamościowymi, integracyjnymi i legitymizacyjnymi. Różne formy i zakres wykorzystania zasobów pamięci przez dziennikarzy newsowych ukazują więc nie tylko zakres respektowania przez nich profesjonalnych standardów, lecz także sposób tworzenia reprezentacji przeszłości. Zarówno tworzenie trafiających do szerokiej publiczności newsów, jak i budowanie wspólnego stosunku wobec zbiorowej przeszłości opiera się na wykorzystaniu odpowiednich struktur narracyjnych.

Różnego rodzaju przywołania przeszłości charakteryzują się dużą siłą oddziaływania i mocą retoryczną, gdyż - w założeniu - bazują na faktach, na tym, co „naprawdę” miało miejsce. Praca dziennikarza to przede wszystkim przekazywanie informacji o tym, jaka jest rzeczywistość. Tworząc newsy, dziennikarze zazwyczaj mniej lub bardziej świadomie odwołują się do specyficznych dla swej profesji reguł i rutynowych praktyk pomagających im zaklasyfikować jakieś wydarzenie do kategorii newsów, wpisać ów news w określony typ informacji, a także wybrać najwłaściwszą konstrukcję i formę narracji (Tuchman, 1972; Berkowitz, 1992; Lule, 2001). Czynniki decydujące o tym, jakie tematy i z jakich powodów stają się przedmiotem newsów, są oczywiście różnorodne (Szwed, 2009), ale w kontekście dziennikarskiej „pracy nad pamięcią" niektóre z nich wydają się ważniejsze od innych. Na przykład Ruth Teer-Tomaselli (2006) uważa, że najważniejszych jest pięć spośród dwunastu czynników wymienianych na klasycznej liście Johana Galtunga i Marie H. Ruge (1965): wielkość i znaczenie, negatywność, potencjał kontynuacji, zaangażowanie elit (osób i krajów) oraz bliskość geograficzna i kulturowa. Ta dyskusyjna interpretacja zwraca uwagę przede wszystkim na proces tworzenia newsów i w zasadzie nie uwzględnia wewnętrznej dynamiki funkcjonowania pamięci zbiorowej, jej złożoności oraz tożsamościowych i legitymizacyjnych funkcji przezeń pełnionych. Pomija także kwestię relacji między czysto informacyjnymi i fikcjonalnymi reprezentacjami przeszłości, interakcje między pamięcią medialną i polityką pamięci oraz złożoność procesu cyrkulacji i odbioru medialnych reprezentacji przeszłości. Znacznie bardziej owocne wydaje się nieco inne podejście - uwzględniające wzajemnie ze sobą powiązane procesy typifikacji, premediacji i remediacji. 
Z typifikacją mamy do czynienia w sytuacji wykorzystania gotowych schematów interpretacyjnych odwołujących się do jakiejś uprzedniej wiedzy pozwalającej przypisać danemu zjawisku pewne cechy typowe lub powiązać to zjawisko z typowym kontekstem (Schütz, 1984). Dziennikarze tworzący newsy klasyfikują bieżące wydarzenia w obrębie jakiejś kategorii, aby możliwe było zastosowanie wobec nich schematów interpretacyjnych, skryptów narracyjnych i form gatunkowych. Obok profesjonalnych standardów dziennikarstwa informacyjnego oraz własnego doświadczenia dziennikarzy ważną rolę odgrywa tu także kulturowo sankcjonowana wiedza o przeszłości i znaczenia stowarzyszone z określonymi wydarzeniami historycznymi.

Premediacja $\mathrm{z}$ kolei dotyczy wpisania treści pamięci w pewną ramę konstrukcyjną, która w określony sposób ukierunkowuje percepcję przyszłych doświadczeń przez odbiorców (Grusin, 2004). W kontakcie z medialnymi przekazami dotyczącymi jakichś treści zbiorowej przeszłości publiczność wykorzystuje uprzednio ukształtowane schematy i standardy ukierunkowujące oczekiwania i interpretacje nowych doświadczeń (Hoskins i O’Loughlin, 2010, s. 90). Mogą one mieć oczywiście różne pochodzenie, w wielu wypadkach wywodzą się z nauki szkolnej, ale duża ich część jest owocem dziennikarskiej kreacji. Podobnie jak publiczność postrzega przeszłość, odwołując się do tych użytecznych schematów, tak też dziennikarze przygotowujący newsy czynią z nich użytek. Treść i forma bieżących newsów podlegają więc determinującym wpływom krążących w ogólnej kulturze pamięci reprezentacji tych wydarzeń ustrukturyzowanych procesami premediacji. Sposób postrzegania, interpretowania oraz włączania informacji dotyczących jakichś wydarzeń z przeszłości $\mathrm{w}$ bieżące newsy będzie zatem w znacznym stopniu zależał od pamięciotwórczych wyobrażeń wynikających z uprzednich kontaktów dziennikarzy z materiałami medialnymi.

Natomiast remediacja polega na pojawianiu się tych samych składników pamięci w różnych mediach, kanałach komunikacji, na różnych nośnikach, wykorzystujących różne sposoby kodowania i przenoszenia znaczeń (Grusin, 2004). Podczas procesów reprodukcji, powielania, upowszechniania, ożywiania i przypominania może dochodzić do mniej lub bardziej znaczących modyfikacji, gdyż zmiana nośnika i kontekstu w sposób nieunikniony wywołuje zmianę znaczenia. Proces remediacji jest obserwowany na przykład podczas wykorzystywania przez dziennikarzy newsowych materiałów wcześniej opublikowanych przez kogoś innego, ich przetwarzania i dostosowywania do wymogów danego medium i macierzystej redakcji. Reprodukowanie i upowszechnianie pod postacią newsów różnych wyobrażeń przeszłości wiąże się 
także z mniejszymi lub większymi zmianami znaczeń związanych z tymi reprezentacjami.

Praca nad zbiorową pamięcią jest realizowana nie tylko przez jednostkowych dziennikarzy starających się o dobre, uwzględniające szersze konteksty, relacjonowanie aktualnych wydarzeń. Ważną rolę odgrywają tu też same instytucje medialne, zwłaszcza te, które posiadają bogate archiwa. B. Zelizer zwraca uwagę na dwie kategorie przedsięwzięć realizowanych przez te instytucje, w których uczestniczą dziennikarze (Zelizer, 2008, s. 385). Pierwsza kategoria obejmuje wszelkiego rodzaju projekty organizowane przez instytucje medialne, intencjonalnie ukierunkowane na przypominanie, przywracanie pamięci czy upowszechnianie jakichś wizji przeszłości. Należą tu na przykład odpowiednie programy, organizacja wydarzeń retrospektywnych, wydawnictwa, publikacje, raporty ukazujące, jak wyglądała praca dziennikarzy lub określonej instytucji medialnej w przeszłości. Poszczególne redakcje tworzą także swoje własne archiwa, w których są przechowywane różnego rodzaju informacje dotyczące przeszłych wydarzeń z historii społeczeństwa, w obrębie którego redakcja funkcjonuje, lub też z historii samej redakcji. Jest to niezwykle ważna funkcja wypełniana przez wszystkie instytucje działające w polu komunikacji medialnej. Dziennikarze mogą korzystać z tych archiwów, przygotowując własne materiały. Ponadto, poprzez uczestnictwo w różnych przedsięwzięciach realizowanych przez macierzystą instytucję medialną, które zazwyczaj przyjmują określoną perspektywę spojrzenia na przeszłość, uzyskują istotne wskazówki dotyczące preferowanych przez redakcję sposobów interpretacji procesów, wydarzeń i postaci historycznych. Druga kategoria przedsięwzięć obejmuje działania samych dziennikarzy i dotyczy własnych materiałów dziennikarskich przygotowanych w przeszłości. Wielu dziennikarzy po latach sięga do własnych doświadczeń i tematów poruszanych niegdyś „na gorąco" i stara się o ich uzupełnienie, inne naświetlenie bądź rozwiązanie dotychczas nierozwiązanych zagadek. Fragmenty lub nawet całość wcześniej przygotowanych materiałów stają się podstawą dla wypracowywania nowych produktów i udostępniania ich publiczności.

\section{TYPY PRZYWOŁAŃ PRZESZŁOŚCI W DZIENNIKARSTWIE NEWSOWYM}

Formy, zakres i waga odwołań do przeszłości i wspólnych zasobów pamięci są bardzo różnorodne, podobnie jak i funkcje pełnione przez te odwołania. 
K. Lang i G.A. Lang wskazują, że realizują one kilka podstawowych celów. Pierwszym z nich jest ustanowienie granicy między teraźniejszością i przeszłością poprzez akcentowanie zmiany jakiegoś zjawiska w czasie. Drugim celem jest poszukiwanie analogii i podobieństw, aby ukazać jakieś ogólniejsze prawidłowości. Trzecim zaś jest dostarczanie kryteriów oceny bieżących wydarzeń poprzez poszerzenie perspektywy, natomiast czwartym - udostępnianie skrótowych wyjaśnień poprzez wskazanie przyczyn stanu aktualnego (Lang i Lang, 1989).

Nieco inaczej na to zagadnienie patrzy Edy, która kładzie nacisk na same sposoby użycia zasobów zbiorowej pamięci przez dziennikarzy informacyjnych. Autorka ta wyodrębnia trzy takie sposoby: komemoracje, analogie historyczne i historyczne konteksty (Edy, 1999).

\subsection{DZIENNIKARSTWO KOMEMORATYWNE (WSPOMNIENIOWE, ROCZNICOWE)}

Newsy komemoratywne nie dotyczą bezpośrednio przeszłości, ale wydarzeń aktualnych. Ich celem jest przede wszystkim relacjonowanie różnego rodzaju wydarzeń, uroczystości, obchodów, wystąpień itp., które mają miejsce dzisiaj. Przeszłość jest natomiast wpisana $\mathrm{w}$ istotę wydarzeń relacjonowanych przez dziennikarzy, w niej tkwi ich geneza, forma i przebieg. Zazwyczaj chodzi tu o wydarzenia ważne dla oficjalnego wymiaru pamięci zbiorowej, co umożliwia ramowanie relacji z bieżących wydarzeń za pomocą usankcjonowanych zasobów pamięci oficjalnej. Dziennikarze mogą jednak również odwoływać się do pamięci nieoficjalnej, oddolnej, aby zaoferować interpretacje alternatywne, opozycyjne względem tych oficjalnych.

J.A. Edy wskazuje, że możemy mieć do czynienia z kilkoma bardziej szczegółowymi formami dziennikarstwa komemoratywnego (Edy, 1999, s. 74-75). Te różne postaci mogą wynikać z faktu, że relacjonowane wydarzenie upamiętnia przeszłe wydarzenie, ma miejsce w rocznicę przeszłego wydarzenia albo też dotyczy jakiejś osoby uczestniczącej w tych przeszłych wydarzeniach (np. pogrzeb). Dla informacji tego typu charakterystyczne jest jednak, że nie budują one znaczącej relacji między przeszłością a teraźniejszością. Przeszłość jest tutaj zamkniętym rozdziałem czasu, jest wyraźnie odrębna od tego, co dzisiaj. Jednocześnie jednak zdarza się, że nawet takie traktowanie przeszłości może się stać impulsem do podejmowania refleksji i publicznych dyskusji nad nią. Dzieje się tak, gdy relacjonowane obchody czy rocznice wzbudzają różnego rodzaju społeczne kontrowersje. Newsy mogą wtedy się skupiać wokół tych kontrowersji, znajdujących publiczny wyraz na przykład w różnych formach kontestacji i protestu. 


\subsection{BUDOWANIE ANALOGII HISTORYCZNYCH}

Informacje tego typu, w przeciwieństwie do wyżej omówionych, wprost nawiązują do przeszłości i wykorzystują elementy zbiorowej pamięci jako narzędzia wyjaśniania aktualnych wydarzeń, a nawet przewidywania przyszłego ich biegu. Relacjonowane wydarzenia dnia dzisiejszego są przedstawiane jako podobne, wręcz analogiczne do tych, które miały miejsce dawniej, np. omawiając działania podjęte w reakcji na jakiś kryzys, przywołuje się kryzysy wcześniejsze. Źródła tych historycznych analogii mogą być zewnętrzne, gdy np. pojawiają się one w cytowanych oficjalnych wypowiedziach. Niekiedy jednak dziennikarze informacyjni sami budują takie analogie, choć rzadko są skłonni przyznać, że w miejsce relacji o faktach proponują interpretacje faktów. Umieszczają w ten sposób aktualne wydarzenia w określonej ramie pamięciowej, której symboliczna treść może jednoznacznie ukierunkowywać sposób odbioru newsów. Zawarte w newsach analogie historyczne mogą także sugerować określone rozwiązania problemów, jakie łączą się z relacjonowanymi wydarzeniami. Mamy wtedy do czynienia ze specyficzną formą pamięci prospektywnej, czyli pamiętaniem lub przypominaniem, aby możliwe było podejmowanie jakichś działań w przyszłości (McDaniel i Einstein, 2007). Edy zwraca też uwagę, że analogie historyczne w dziennikarstwie newsowym bywają atrakcyjne i sugestywne, ale ich wykorzystanie często jest ryzykowne. Mogą bowiem zagrażać naidenterpretacją, opierać się na założeniu o powtarzalności historii, grozić przeoczeniem tego, co w bieżących wydarzeniach nowe i unikalne, bądź też wykazywać podatność na alternatywne interpretacje. Proces budowania analogii historycznych, mocno związany z teraźniejszością i przyszłością, zazwyczaj jednak nie pobudza do jakiejś pogłębionej refleksji nad treściami zbiorowej pamięci. W przekazach informacyjnych pełnią one funkcje raczej marginalne, działają jako ilustracja, model, symbol, ozdobnik retoryczny lub perswazyjny, ale w niewielkim stopniu zachęcają do zastanawiania się nad tym, co i jak powinno się pamiętać.

\subsection{TWORZENIE KONTEKSTÓW HISTORYCZNYCH}

Ten typ odwołań do przeszłości służy nakreśleniu pewnej trajektorii wydarzeń prowadzących do teraźniejszego wydarzenia lub stanu. Z racji specyfiki informacji przekazywanych jako newsy zazwyczaj konteksty te są dość ubogie treściowo, wąskie i fragmentaryczne. Przyczyną pewnych obaw dziennikarzy przed nakreślaniem kontekstów historycznych może być dążenie do jak największej obiektywności, której standardy mogłyby zostać naruszone poprzez budowanie jednoznacznego łańcucha przyczyn i skutków. Takie łączenie 
wydarzeń w łańcuch przyczynowo-skutkowy jest bardziej ryzykowne aniżeli budowanie analogii, gdyż te drugie mają charakter nieco metaforyczny (Edy, 1999, s. 80). W wielu jednak przypadkach związki między wydarzeniami są na tyle jednoznaczne, że możliwe jest ich połączenie. Innym wykorzystaniem historycznych kontekstów jest prezentacja sylwetek ważnych postaci publicznych, gdzie przywoływane są wydarzenia historyczne, w których te postaci brały udział. W przypadku budowania historycznych kontekstów również mamy do czynienia z pewnym ryzykiem. Wiąże się ono na przykład z kwestią dość arbitralnej selekcji wydarzeń, które mają doprowadzić do wydarzenia aktualnego, selekcji pomijającej wszystkie inne składniki procesu historycznego.

Ogólnie rzecz biorąc, wszystkie te typy odwołań do przeszłości w dziennikarstwie newsowym nie są ukierunkowane bezpośrednio na wspominanie czy utrwalanie pamięci o wydarzeniach z przeszłości, ale na pełniejsze wyjaśnianie tego, z czym mamy do czynienia obecnie. Przywołaniom zasobów zbiorowej pamięci towarzyszą różne cele, często są one używane jako środek dramatyzacji, chwyt perswazyjny czy ozdobnik formalny. Wprawdzie funkcje pamięciotwórcze nie należą do pierwszoplanowych, niemniej jednak sprzyjają utrwalaniu i hierarchizowaniu pewnych wątków treściowych ugruntowanych w ogólnej kulturze pamięci publiczności.

\section{WNIOSKI}

W interesującym wywiadzie poświęconym kondycji współczesnego dziennikarstwa Matt Taibbi skonstatował istnienie głębokich podziałów polityczno-ideologicznych między poszczególnymi organizacjami medialnymi i dziennikarzami: „Dziennikarze po obu stronach mówią: oto moja publiczność, wiem, czego chcą, wiem, co myślą, i to ode mnie dostaną. Dają im to, co się sprzeda. Jedyna różnica polega na tym, co chcą usłyszeć odbiorcy. [...] Sprzedają podziały, na pewno też tożsamość. Ale myślę, że przede wszystkim sprzedają ludziom obraz ich samych" (Taibbi, 2021). Jeśli powyższa diagnoza trafnie rozpoznaje główne tendencje (i bolączki) dzisiejszego dziennikarstwa, to zachęca jednocześnie do stawiania pytań o sposoby selekcjonowania i wykorzystywania zasobów pamięci przez dziennikarzy koncentrujących się na kształtowaniu i potwierdzaniu tożsamości partykularnych segmentów publiczności. Ponieważ tożsamości te pozostają w stanie permanentnego napięcia, prowadzącego raczej do uwydatnienia różnic aniżeli poszukiwania wspólnoty, 
można przypuszczać, że podporządkowanie pamięci takim wysoce instrumentalnym celom ma poważne konsekwencje dla funkcjonowania całościowej kultury pamięci zbiorowości. W radykalnej postaci pamięć kształtowana przez dziennikarzy newsowych przypominałaby przypadkowy i niespójny wewnętrznie zbiór reprezentacji przeszłości, dostosowany wyłącznie do dziennikarskich wyobrażeń o potrzebach i oczekiwaniach określonego segmentu odbiorców. Zagadnienie to wymaga pogłębionych badań uwzględniających zarówno perspektywę dziennikarzy, jak i publiczności. Innym interesującym tematem przedsięwzięć badawczych, nasuwającym się w związku z rosnącą aktywnością dziennikarzy informacyjnych w mediach społecznościowych, angażujących przede wszystkim młodszych użytkowników sieci, są sposoby wykorzystywania przez dziennikarzy reprezentacji przeszłości w tym specyficznym środowisku komunikacyjnym. Ze względu na wysoką konkurencyjność panującą w tym środowisku, odmienne zdefiniowanie roli dziennikarza oraz szczególne reguły tworzenia i krążenia treści stawianie pytań o formy obecności i treść przedstawień przeszłości proponowanych przez dziennikarzy wydaje się szczególnie zasadne.

\section{BIBLIOGRAFIA}

Barnhurst K.G. (2003), The makers of meaning: National Public Radio and the new long journalism, 1980-2000, Political Communication, nr 20(1), s. 1-22.

Berkowitz D. (1992), Non-routine news and newswork: Exploring a what-a-story, Journal of Communication, $\mathrm{nr}$ 42(1), s. 82-94.

Dyczewski L. (2011), Kultura w całościowym planie rozwoju, Warszawa: Instytut Wydawniczy PAX.

Edy J.A., Daradanova M. (2006), Reporting through the lens of the past. From Challenger to Columbia, Journalism nr 7(2), s. 131-151.

Edy J.A. (1999), Journalistic uses of collective memory, Journal of Communication, $\mathrm{nr}$ 49(2), s. 71-85.

Erll A. (2018), Kultura pamięci. Wprowadzenie, posłowie i red. naukowa M. Saryusz-Wolska, Warszawa: Wydawnictwa Uniwersytetu Warszawskiego.

Galtung J., Ruge M.H. (1965), The structure of foreign news: The presentation of the Congo, Cuba and Cyprus crises in Four Norwegian Newspapers, Journal of Peace Research, nr 2(1), s. 64-90.

Grusin R.A. (2004), Premediation, Criticism, nr 46(1), s. 17-39.

Hoskins A., O'Loughlin B. (2010), War and media: The emergence of diffused war, Cambridge: Polity Press.

Huyssen A. (1995), Twilight memories: marking time in a culture of amnesia, New York: Routledge.

Kitch C. (2005), Pages from the past: History and memory in American magazines, Chapel Hill: University of North Carolina Press.

Kula M. (2002), Nośniki pamięci historycznej, Warszawa: Wydawnictwo DiG 2002.

Lang K., Lang G.E. (1989), Collective memory and the news, Communication, nr 11, s. 123-129. 
Lule J. (2001), Daily news, eternal stories: The mythological role of journalism, New York: Guilford Press.

McDaniel M.A., Einstein, G.O. (2007), Prospective memory: An overview and synthesis of an emerging field, Thousand Oaks, CA, Sage.

Meyers O. (2002), Still photographs, dynamic memories: an analysis of the visual presentation of Israel's history in commemorative newspaper supplements, Communication Review, 5(3), s. 179-205.

Mihelj S. (2009), Television news and the dynamics of national remembering, [w:] E. Castello, A. Dhoest, H. O'Donnell (red.), The nation on screen: Discourses of the national on global television, Cambridge: Cambridge Scholars Publishing, s. 119-138.

Schudson M. (1992), Watergate in American memory: How we remember, forget and reconstruct the past, New York: BasicBooks.

Schütz A. (1984), Potoczna i naukowa interpretacja ludzkiego działania, [w:] E. Mokrzycki (red.), Kryzys i schizma. Antyscjentystyczne tendencje w socjologii wspótczesnej, Warszawa: Państwowy Instytut Wydawniczy, t. 1, s. 137-192.

Szwed R. (2009), Proces produkcji informacji: od gatekeepera do public relations, [w:] L. Dyczewski (red.), Jaka informacja?, Lublin-Warszawa: Wydawnictwo KUL, Centrum Europejskie Natolin, s. 53-73.

Taibbi M. (2021), Pandemia przyspieszyła polaryzację. Wywiad przeprowadził K. Cieślik, Rzeczpospolita: Plus-Minus, 20-21.02.2021.

Teer-Tomaselli R. (2006), Collective memory and media news, Global Times. The Communication for Development Journal, nr 5.

Tuchman G. (1972), Objectivity as strategic ritual: An examination of newsmen's notion of objectivity, American Journal of Sociology, nr 77(4), s. 660-679.

Zandberg E., Meyers O., Neiger M. (2012), Past continuous newsworthiness and the shaping of collective memory, Critical Studies in Media Communication, nr 29(1), s. 65-79.

Zandberg E. (2010), The right to tell the (right) story: Journalism, authority and memory, Media, Culture \& Society, nr 32(1), s. 5-24.

Zelizer B. (1992), „Covering the body”: The Kennedy assassination, the media and the shaping of collective memory, Chicago: University of Chicago Press.

Zelizer B. (2008), Journalism's memory work, [w:] A. Erll, A. Nünning (red.), Cultural memory studies: An international and interdisciplinary handbook, Berlin-New York: Walter de Gruyter, s. 379-387.

Zelizer B. (1993), News: First or final draft of history?, Mosaic, 2(1), s. 2-3.

Zelizer B. (2004), When war is reduced to a photograph, [w:] S. Allan, B. Zelizer (red.), Reporting war: Journalism in wartime, London: Routledge, s. 115-135. 


\section{PAMIECĆ ZBIOROWA I DZIENNIKARSTWO NEWSOWE}

\section{Streszczenie}

Głównym celem artykułu jest analiza relacji między dziennikarstwem newsowym a pamięcią zbiorową. Uwzględniając podstawowe zasady funkcjonowania dziennikarstwa newsowego, ukazano tu specyfikę form odniesień do przeszłości, jakie pojawiają się w medialnych materiałach informacyjnych. Jako najbardziej znaczące procesy określające sposoby obecności treści pamięci w newsach wskazano typifikację, premediację i remediację. Omówiono także główne typy odwołań do przeszłości funkcjonujące w obrębie dziennikarstwa newsowego.

Słowa kluczowe: newsy; dziennikarstwo newsowe; pamięć zbiorowa; reprezentacje przeszłości.

\section{COLLECTIVE MEMORY AND NEWS JOURNALISM}

\section{Summary}

The main goal of the article is to analyze the relationship between news journalism and collective memory. Based on the basic principles of news journalism, the specifics of the forms in which references to the past appear in media information materials are shown. Typification, premeditation and remediation were indicated as the most significant processes determining the ways of the presence of memory content in news. The main types of references to the past within news journalism were also discussed.

Keywords: news; news journalism; collective memory; representations of past. 